\title{
Physical activity and lower-back pain in persons with traumatic transfemoral amputation: A national cross-sectional survey
}

\author{
Hemakumar Devan, MPhty; Steve Tumilty, PhD; Cath Smith, PhD* \\ Centre for Physiotherapy Research, School of Physiotherapy, University of Otago, Dunedin, New Zealand
}

\begin{abstract}
Lower-back pain (LBP) is a common secondary condition following lower-limb amputation. The purpose of this study was to investigate LBP prevalence and the relationship between LBP and physical activity (PA) levels in a national sample of persons with traumatic transfemoral amputation (TFA). Questionnaires were mailed to a random sample of people with traumatic TFA $(n=322)$ from the New Zealand Artificial Limb Board national database. Of the participants who completed the survey (55\% response rate), $64.1 \%$ reported LBP and $39.1 \%$ reported restricted PA due to LBP. There was no relationship between the PA levels of persons with and without LBP (chi-square $=2.11, p>0.05$ ). There was an equal distribution of persons with LBP in low, medium, and high PA subgroups. However, persons who reported restricted PA due to LBP had lower PA scores than persons with LBP and no restricted PA (chi-square $=11.56, p<0.05$ ). Based on our results, LBP is prevalent in the traumatic TFA population. PA levels are not influenced by the presence or absence of LBP. However, future studies investigating LBP coping strategies and using objective PA outcome measures might further elucidate the relationship between PA and LBP in this population.
\end{abstract}

Key words: activity, amputation, back pain, limb loss, lowerlimb amputation, physical activity, prevalence, secondary complication, survey, trauma.

\section{INTRODUCTION}

Lower-back pain (LBP) continues to be a major health and socioeconomic problem, with an estimated point prevalence of 12 percent in the general population
[1]. It is one of the most frequently reported musculoskeletal problems in persons with disability [2-3]. Furthermore, LBP is more common in the population with lower-limb amputation (LLA) than in people with other causes of disability (such as stroke and cerebral palsy), with a high prevalence rate ranging from 52 to 80 percent [4-7]. In at least one-third of people with LLA, LBP is constant and bothersome [7] and associated with poor quality of life [8-9] and depression [10]. In recent years, studies have reported a greater prevalence of LBP in people with LLA than other common comorbidities such as phantom pain and residual-limb pain $[6,10]$.

In people with LLA, biomechanical factors seem to play a significant role in contributing to LBP [11]. In particular, the abnormal spinal kinematics secondary to walking with prosthesis is considered to be a significant contributor [12-13]. Literature supports the hypothesis that, with more

\footnotetext{
Abbreviations: $\mathrm{ADL}=$ activity of daily living, $\mathrm{BMI}=$ body mass index, $\mathrm{CI}=$ confidence interval, $\mathrm{LBP}=$ lower-back pain, LLA = lower-limb amputation, MET = metabolic equivalent, $\mathrm{NZ}=$ New Zealand, NZALB = New Zealand Artificial Limb Board, PA = physical activity, PASIPD = Physical Activity Scale for Individuals with Physical Disabilities, TFA $=$ transfemoral amputation.

*Address all correspondence to Cath Smith, PhD; Centre for Physiotherapy Research, School of Physiotherapy, PO Box 56, University of Otago, Dunedin 9016, New Zealand; +64-3-479-7476; fax: +64-3-479-8414.

Email: cath.smith@otago.ac.nz

http://dx.doi.org/10.1682/JRRD.2011.09.0155
} 
proximal levels of amputation, there is a corresponding increase in the energy cost of walking [14-15] and abnormal gait patterns [16-17]. These factors could contribute to people with transfemoral amputation (TFA) having a higher prevalence, severity, and associated disability of LBP than in populations with other levels of LLA [6,18]. In light of these findings, further research is needed to investigate the contributions of physical activity (PA) patterns to LBP in this population [19].

In the general population, the role of PA (leisure, household, and occupational activities) and its association with LBP has been more frequently investigated in the recent decades [20]. Certainly, the beneficial effects of moderate daily PA on physical and mental health are well established [21-22]; however, the role of PA as a possible contributing factor to LBP is also reported [23]. Campello et al. proposed a theoretical model of U-shaped relationship between PA and LBP, where either too little or excessive PA levels could increase the possibility of LBP [24]. The only systematic review that investigated the relationship between PA levels and LBP reported inconclusive evidence for the association between PA levels and LBP because of heterogeneity in the methodology of included studies and the complexities of PA measurement [25].

Despite a number of studies exploring the relationship between LBP and PA in the general population, the investigation of PA levels in persons with disability has received minimal attention in the literature [26-27]. To our knowledge, the only study to investigate the relationship between LBP and PA in TFA reports a lack of significant association between LBP and PA levels [28]. However, the sample included TFAs of multiple causes, including vascular disease and malignancy, which could have confounded the results. People with vascular amputation are older [29] and less ambulatory [14,30], and the associated age-related comorbidities (e.g., cardiovascular problems) could influence both PA levels and LBP-related disability. In contrast, people with traumatic amputation are generally younger and more active prosthesis users than people with vascular amputation [30-31].

In New Zealand (NZ), approximately 4,000 people are currently living with limb loss [32]. It is estimated that 400 persons undergo amputation annually, and this rate has increased considerably over the past decade [32]. This is the first study to investigate the prevalence of LBP and its association with PA levels in an NZ population. The results of our study will enhance understanding about LBP prevalence, associated disability, and PA levels among the population with traumatic TFA.

The purposes of this national cross-sectional survey were to (1) determine the prevalence of LBP, (2) investigate the relationship between the self-reported PA levels of persons with and without LBP, (3) explore the relationship between the PA levels of persons with and without restricted activities of daily living (ADLs) due to their LBP, and (4) characterize the relationship between LBP and amputation-related parameters and demographic variables.

\section{METHODS}

\section{Study Design}

We conducted a cross-sectional survey in collaboration with the New Zealand Artificial Limb Board (NZALB), a government organization that provides prosthetic services for NZ residents with amputation. We extracted a contact list of all participants with traumatic TFA from the NZALB database (updated in 2006). This consisted of 458 participants, and we selected a random sample of 322 participants using a computer-generated numbers list. According to the Dillman sample size estimation equation [33] for a population of 458, a sample of 209 participants was needed at a 95 percent confidence interval $(\mathrm{CI})$ with a \pm 5 percent sampling error and assuming a 50/50 split in choosing the responses (yes or no) for the LBP question. Based on the results of similar previous studies [4,28], we calculated the sample size $(n=322)$ assuming a response rate of 65 percent.

\section{Participants}

We included participants age $\geq 18 \mathrm{yr}$ with a history of traumatic TFA and minimum prosthesis usage for a period of 6 mo since amputation. We excluded participants if they had any of the following: (1) TFA due to complications from peripheral vascular diseases, diabetes, and tumors; (2) other levels of LLA (i.e., below-knee, foot, and bilateral amputation); and (3) a history of lumbar spine surgery.

\section{Survey Implementation}

We mailed a total of 322 questionnaires (Appendix, available online only) by post along with a cover letter, consent form, and postage-paid return envelope. We requested that participants return the completed questionnaire within a period of $2 \mathrm{wk}$. We sent an additional reminder letter and 
replacement questionnaire to nonrespondents $3 \mathrm{wk}$ after the initial mail-out in order to maximize the response rate [34].

\section{Measures}

The questionnaire consisted of three domains: (1) demographics and history of amputation, (2) LBPrelated questions, and (3) PA-related questions.

\section{Lower-Back Pain Questions}

We adapted the "optimal" LBP definition recommended for conducting prevalence studies in LBP [35]. We asked participants whether they had LBP in the past 4 wk using a yes or no question and whether the pain was severe enough to restrict their ADLs for more than $1 \mathrm{~d}$. The questions on LBP severity were quantified on a 0 to 10 rating scale, where $0=$ no pain and $10=$ pain as bad could be, and classified as mild (1-4), moderate (5-6), and severe $(\geq 7)$ based on similar previous studies [4,36-37].

\section{Physical Activity Questions}

We assessed PA using the Physical Activity Scale for Individuals with Physical Disabilities (PASIPD). The PASIPD is a 13-item, $7 \mathrm{~d}$ recall questionnaire with subscales measuring the PA levels of leisure, household, and occupational activities. We calculated the PA scores by multiplying the average hours per day of each PA by a corresponding metabolic equivalent (MET) value and summed the individual PA scores to calculate the total PA score in MET hours per day. Previous studies have reported the reliability [38], construct [39], and criterion validity $[38,40]$ of the PASIPD in persons with disability (including amputation), and the results were comparable with other self-reported PA questionnaires.

\section{Analysis}

We used descriptive statistical analyses to describe the LBP prevalence and characteristics. Because of a lack of standard criteria in classifying PA levels and skewed PA scores, we divided the total PA scores (i.e., the sum of leisure, household, and occupational PA scores) into three equal tertiles (low, middle, and high) [41]. We analyzed the following relationships using chi-square $\left(\chi^{2}\right)$ contingency table analysis: (1) relationship between LBP yes/no and the PA tertiles, (2) relationship between the respondents reporting LBP without ADL restriction and no LBP, and (3) relationship between the LBP groups with and without ADL restriction and their PA tertiles.

We analyzed the relationship between LBP and other variables (age, sex, height, weight, body mass index [BMI], and years since amputation) using binomial logistic regression. We reported odds ratios with 95 percent CIs. We performed analyses using SPSS version 19 (IBM Corporation; Armonk, New York) and considered $p<0.05$ significant.

\section{RESULTS}

Of the questionnaires we mailed $(n=322)$, the NZ postal service returned 18 as undeliverable. Thus, a maximum of 304 respondents could have completed the survey. Of the 176 surveys we received ( 87 from mailing 1 and 89 from mailing 2), 10 respondents indicated that they did not want to participate, yielding a response rate of 55 percent (166/304). We excluded the data of 19 respondents because of other levels of amputation $(n=3)$, incomplete data $(n=1)$, and other causes of TFA $(n=15)$. Thus, we included data from 145 respondents for analysis.

\section{Participants}

Table 1 describes the characteristics of the respondents. Most notable from this data is the predominance of men $(82.8 \%)$ and NZ Europeans (81.1\%), with a mean age of $56.8 \mathrm{yr}$. Moreover, the mean time since amputation was $27 \mathrm{yr}$, which indicated that the traumatic event occurred in participants' late 20s.

\section{Lower-Back Pain Prevalence}

LBP was reported by 64.1 percent (95\% CI: $57.4 \%-$ $70.8 \%$ ) of respondents (Figure 1). In those with LBP $(n=93)$, a majority of the respondents $(61 \%$ [56/92] $)$

Table 1.

Participant characteristics $(n=145)$.

\begin{tabular}{lc}
\hline \multicolumn{1}{c}{ Characteristic } & Total \\
\hline Sex (\% male) & 82.8 \\
Age Range, yr (mean \pm SD) & $18-93(56.8 \pm 14.6)$ \\
Ethnicity, $n(\%)$ & $118(81.1)$ \\
NZ European & $18(12.6)$ \\
Māori & $8(5.6)$ \\
Other & $1-66(27.1 \pm 16.1)$ \\
Time Since Amputation Range, yr (mean $\pm \mathrm{SD})$ & $24.1(10.7-37.6)$ \\
Physical Activity, median (interquartile range) & $48(\leq 13.6)$ \\
Low, $n(\mathrm{MET}$ h/d) & $48(13.6-32.5)$ \\
Medium, $n(\mathrm{MET}$ h/d) & $49(\geq 32.5)$ \\
High, $n($ MET $\mathrm{h} / \mathrm{d})$ & \\
*One missing value $(n=144)$. & \\
MET $=$ metabolic equivalent, NZ = New Zealand, SD $=$ standard deviation. \\
\hline \hline
\end{tabular}




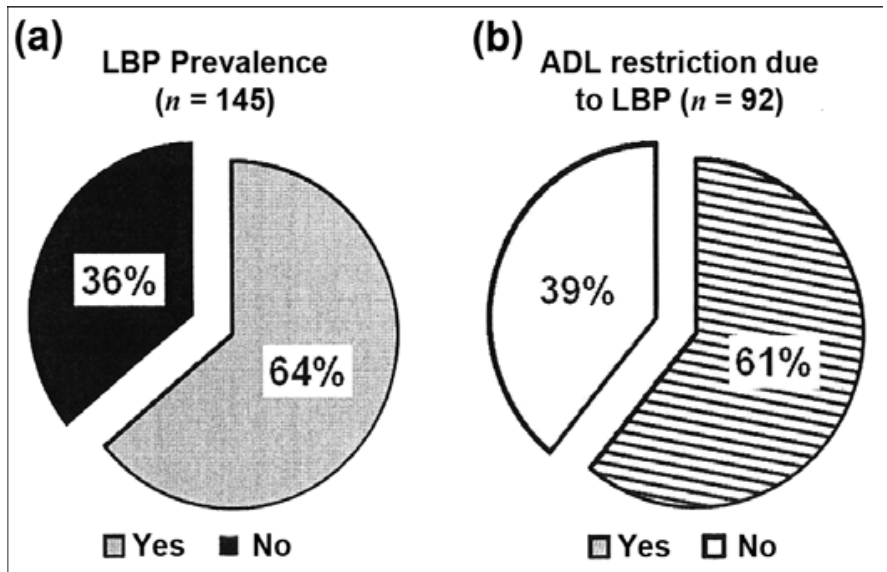

Figure 1.

(a) Lower-back pain (LBP) prevalence in New Zealand population with traumatic transfemoral amputation surveyed (64\%) along with (b) percentage of those with LBP experiencing activity of daily living (ADL) restrictions due to pain (39\%).

reported no interference with ADLs because of their LBP (Figure 1). For the $4 \mathrm{wk}$ preceding completion of the survey, 20 percent reported LBP on almost every day. The pain intensity for the majority of the respondents (59\%) was mild (1-4); however, 14 percent reported severe $(\geq 7)$ LBP. The majority of respondents with LBP (38.7\%) reported that it was more than $3 \mathrm{yr}$ since they had a whole month without LBP (Table 2).

The demographic characteristics of the LBP yes and no groups did not differ (Table 3); however, the increased incidence of residual-limb problems in the LBP yes group was statistically significant $\left(\chi^{2}=11.56, p<\right.$ $0.05)$ compared with the LBP no group.

\section{Relationship Between Lower-Back Pain and Physical Activity Levels}

We found no association between LBP (yes or no) and PA levels $\left(\chi^{2}=2.11, p=0.72\right)$ (Figure 2). We found no association between the respondents reporting LBP with no ADL restriction and those with no $\mathrm{LBP}\left(\chi^{2}=1.08, p=\right.$ 0.58 ) (Figure 2). The group reporting LBP and ADL restriction (LBP+ADL restriction) had significantly lower PA levels than the group without ADL restriction (LBPADL restriction) (Figure 3). In relation to other confounding factors, only age at assessment had a significant negative relationship in predicting LBP (i.e., increasing age was associated with lower odds for reporting LBP) (Table 4).
Table 2.

Lower-back pain characteristics $(n=93)$.

\begin{tabular}{lc}
\hline \multicolumn{1}{c}{ Characteristic } & Distribution (\%) \\
\hline Interference with ADL* ${ }^{*}$ & $36(39.1)$ \\
Yes & $56(60.9)$ \\
No & \\
Frequency & \\
On Some Days & $43(46.7)$ \\
On Most Days & $30(32.6)$ \\
Everyday & $19(20.6)$ \\
Average Pain Intensity & \\
Mild (1-4) & $55(59.1)$ \\
Moderate (5-6) & $25(26.9)$ \\
Severe (7-10) & $13(14.0)$ \\
Duration (last pain-free month) & \\
$<3$ mo & $26(28.0)$ \\
$3-7$ mo & $17(18.3)$ \\
7 mo-3 yr & $10(10.8)$ \\
$>3$ yr & $36(38.7)$ \\
Unknown & $4(4.3)$ \\
\hline One missing value $(n=144)$. & \\
ADL = activity of daily living. & \\
\hline \hline
\end{tabular}

\section{DISCUSSION}

Our results are the first to investigate LBP prevalence in the national NZ sample of people with traumatic TFA and to report on the relationship between LBP and selfreported PA levels. Based on our results, there was no relationship between self-reported PA levels of persons with and without LBP. In fact, two-thirds of participants with LBP reported moderate to high PA levels, and participants who reported ADL restriction due to LBP had lower PA levels than those who reported no ADL restriction due to their LBP.

Because of lack of LBP prevalence data in the general population of NZ, a direct comparison of our results could not be made. However, LBP prevalence in 64 percent of people with TFA is approximately twice that reported in the general population [42-43]. Our result of LBP prevalence in people with TFA (64\%) concurs with similar previous studies in the amputation literature [4,6-7]. Despite the variations in the selection criteria and the LBP definition utilized in previous studies, the recall period (4 wk) in reporting LBP symptoms was consistent with previous studies [4,7]. Our result of ADL restriction in 39 percent of respondents caused by LBP is in line with previous studies on LLA $[4,28,37]$. Moreover, the majority 
Table 3.

Prevalence of lower-back pain by demographic characteristic, $n(\%)$.

\begin{tabular}{|c|c|c|}
\hline \multirow{2}{*}{ Measure } & \multicolumn{2}{|c|}{ Lower-Back Pain } \\
\hline & Yes & No \\
\hline \multicolumn{3}{|l|}{$\operatorname{Sex}(n=142)$} \\
\hline Male & $73(80.2)$ & $44(86.3)$ \\
\hline Female & $18(19.8)$ & $7(13.7)$ \\
\hline \multicolumn{3}{|l|}{ Age, yr $(n=140)$} \\
\hline $18-45$ & $25(28.1)$ & $7(13.7)$ \\
\hline $46-65$ & $43(48.3)$ & $28(54.9)$ \\
\hline$>65$ & $21(23.6)$ & $16(31.4)$ \\
\hline \multicolumn{3}{|c|}{ Time Since Amputation, yr $(n=142)$} \\
\hline$<2$ & $2(2.2)$ & $3(5.9)$ \\
\hline $2-9$ & $11(12.1)$ & $5(9.8)$ \\
\hline$\geq 10$ & $78(85.7)$ & $43(84.3)$ \\
\hline \multicolumn{3}{|c|}{ Body Mass Index $(n=125)$} \\
\hline$<18.4$ & $1(1.2)$ & $2(5.0)$ \\
\hline $18.5-24.99$ & $22(25.9)$ & $8(20.0)$ \\
\hline $25-29.99$ & $27(31.8)$ & $13(32.5)$ \\
\hline$>30$ & $35(41.2)$ & $17(42.5)$ \\
\hline \multicolumn{3}{|l|}{ Comorbidity $(n=144)$} \\
\hline 0 & 39 (41.9) & $30(58.8)$ \\
\hline 1 & $43(46.2)$ & $19(37.3)$ \\
\hline$\geq 2$ & $11(11.8)$ & $2(3.9)$ \\
\hline \multicolumn{3}{|l|}{ Ex-Smoker $(n=144)$} \\
\hline Yes & $64(68.8)$ & $29(56.9)$ \\
\hline No & $29(31.2)$ & $22(43.1)$ \\
\hline \multicolumn{3}{|c|}{ Residual-Limb Problems $^{*}(n=144)$} \\
\hline Yes & $45(48.4)$ & $11(21.6)$ \\
\hline No & $47(50.5)$ & $40(78.4)$ \\
\hline \multicolumn{3}{|c|}{ Nondisabled-Limb Pain $(n=144)$} \\
\hline Yes & $58(62.4)$ & $26(51.0)$ \\
\hline No & $35(37.6)$ & $25(49.0)$ \\
\hline
\end{tabular}

of our respondents $(>80 \%)$ reported mild to moderate $(<6)$ LBP, which corresponds with a similar investigation on the relationship between LBP intensity and ADL interference in LLA [37]; the study concluded that persons with pain scores $\geq 7$ had greater ADL interference because of LBP than those with scores $\leq 6$. The chronicity of LBP was illustrated by the report from 38 percent of the respondents who indicated that it was more than $3 \mathrm{yr}$ since they had a whole month without LBP. In summary, the high prevalence of LBP in our sample (i.e., two-thirds of participants) clearly suggests that LBP is a common secondary disability in persons following traumatic TFA [4].

In relation to the PA levels, the median PASIPD score of our sample was 24.01 MET h/d (range: 0.65-149.91), which is higher than the mean \pm standard deviation score

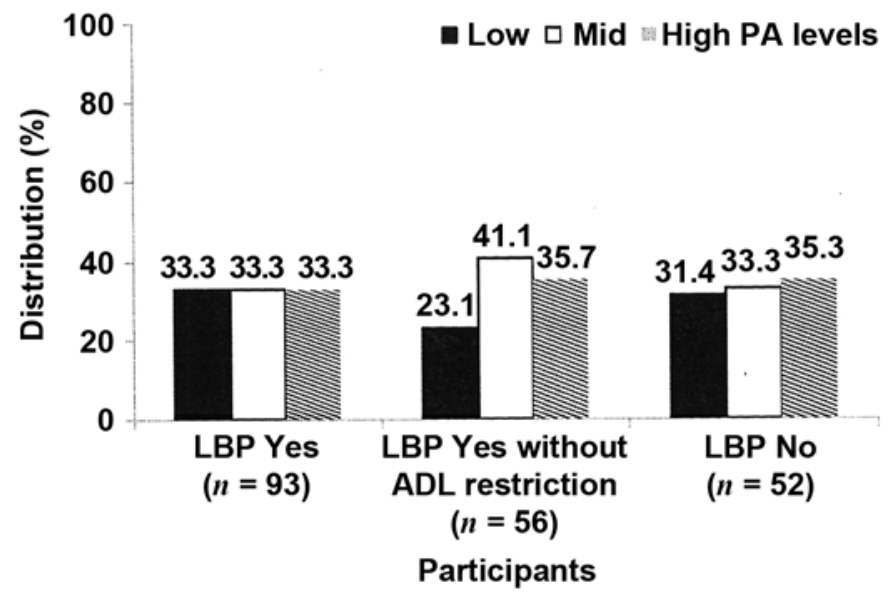

Figure 2.

Relationship between lower-back pain (LBP) and physical activity (PA) levels. Note: Equal distribution of persons with LBP in three PA subgroups (low, middle [mid], high) and distribution of majority of participants with LBP and without activity of daily living (ADL) restriction in middle to high PA subgroups.

of $20.2 \pm 14.5 \mathrm{MET}$ h/d (range: $0.0-67.9$ ) for the sample population (including those with amputation) investigated in the validation of the PASIPD questionnaire [39]. Moreover, two-thirds of our participants $(97 / 145)$ had PA scores $\geq 13.59 \mathrm{MET} h / \mathrm{d}$, which is greater than the recommended daily PA levels for physical and mental health $[22,44]$. The majority of our participants $(96 \%)$ reported current prosthetic use with the time since amputation being $26.9 \pm 16.1 \mathrm{yr}$. Based on these results, we can assume that our sample represented an active prosthetic user group; however, firm conclusions about PA levels could not be made because of lack of a control group and lack of normative data of PASIPD scores in the general population. Our results on the PA levels concur with a similar previous study by Stam et al., which reported that a majority of people with traumatic TFA adopted moderate PA levels [28].

Our results found no relationship between LBP and self-reported PA levels. The presence or absence of LBP did not influence PA levels (low, medium, or high). We also compared the PA levels of persons reporting no ADL restriction due to LBP with those reporting no LBP so as to specifically determine the relationship between current PA levels and its influence on LBP. However, we found no relationship between the groups. In fact, two-thirds of our participants with LBP had moderate to high PA levels, 


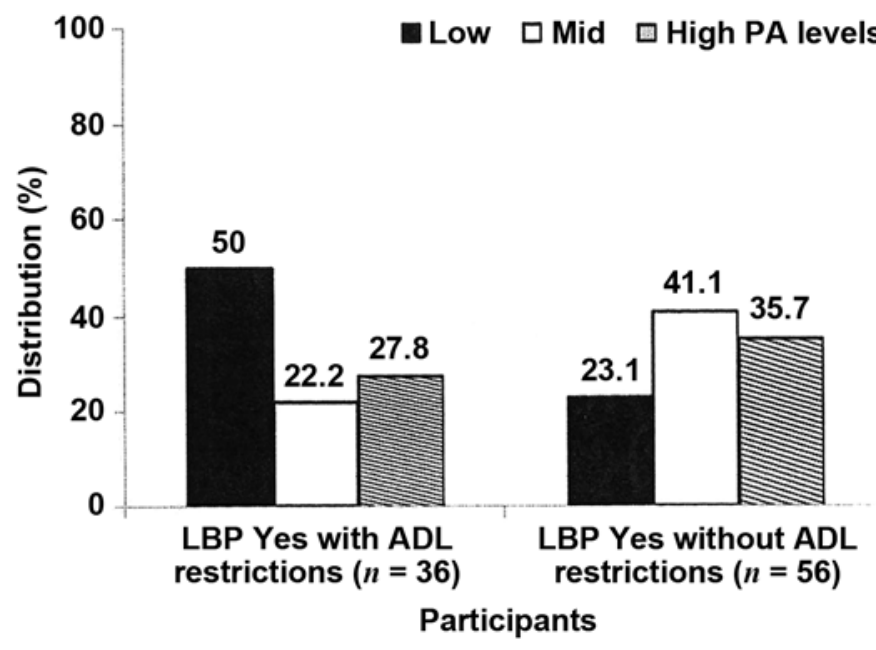

Figure 3.

Physical activity (PA) levels of persons with and without activity of daily living (ADL) restrictions due to lower-back pain (LBP) (Pearson $\left.\chi^{2}=7.4, p=0.02\right)$. Mid = middle.

similar to the PA levels of participants without LBP. A possible explanation for this result could be related to the avoidance-endurance behavior of individuals. According to this model, endurance copers tend to remain active despite the presence of pain and report increased PA levels [45]. Similar results of lack of association between LBP and PA have been reported by studies conducted in the general population [46-47]. However, the presence of moderate to high PA levels in the majority of our participants regardless of their LBP indicates better coping strategies adopted by this population and warrants additional investigation pertaining to PA levels as a risk factor for LBP in this population.

Another finding of note was the presence of low PA levels in persons reporting ADL restriction due to LBP compared with persons who reported no ADL restriction due to LBP. In a recent review investigating the relationship between disability due to LBP and PA levels, there were no significant relationships between self-reported disability and PA levels in persons with acute or subacute LBP $(<3$ mo), while persons with chronic LBP $(>3 \mathrm{mo})$ reporting high disability were more likely to have decreased PA levels [48]. Although our participants reported ADL restriction due to LBP and decreased PA levels, our result should be interpreted with caution because we measured LBP disability based on their response to a yes or no question. Further investigation using LBP disability questionnaires (e.g., Oswestry questionnaire [49]) could have strengthened our results.

The presence of residual-limb problems had a significant relationship with LBP. The majority of the respondents reported the presence of phantom pain, residual-limb shrinkage, and skin problems in the residual limb as major reasons that affected their walking ability. In a study investigating the quality of life in people with nonvascular TFA, the presence of residual-limb and socket-related problems in $>50$ percent of participants was positively associated with poor physical functioning [9]. Despite the common prevalence of residual-limb problems reported in the LLA population [50], our result should be interpreted with caution because of the diverse nature of residual-limb problems and lack of investigation of other factors (type of prosthesis used, residual-limb length, and muscle strength) [51].

Our findings related to the presence of at least one or more comorbidities in 58 percent (54/93), residual-limb problems in 48.4 percent (45/93), and pain in the nonamputated limb in 62.4 percent (58/93) of participants with LBP demonstrates the presence of multiple pain conditions in this population. Our reports are consistent with the results of a national survey conducted in the United States; Ephraim et al. reported the presence of at least one

Table 4.

Relationship between lower-back pain and other amputation-related parameters.

\begin{tabular}{|c|c|c|c|c|}
\hline Covariate & $\boldsymbol{\beta}$ & OR & $95 \% \mathrm{CI}$ & $p$-Value \\
\hline Age (yr) & -0.028 & 0.973 & $0.949-0.099$ & $0.03^{*}$ \\
\hline Sex & -0.461 & 0.631 & $0.244-1.629$ & 0.34 \\
\hline Height (cm) & -0.857 & 0.425 & $0.029-6.225$ & 0.53 \\
\hline Weight (kg) & -0.006 & 0.994 & $0.977-1.011$ & 0.05 \\
\hline Body Mass Index & -0.017 & 0.983 & $0.936-1.032$ & 0.48 \\
\hline Time Since Amputation (yr) & 0.002 & 1.002 & $0.981-1.024$ & 0.08 \\
\hline
\end{tabular}

${ }^{*} p<0.05$.

$\beta=$ beta coefficient, $\mathrm{CI}=$ confidence interval, $\mathrm{OR}=$ odds ratio. 
of the chronic pain conditions (i.e., phantom pain, residuallimb pain, and LBP) in 95 percent of their sample population [5]. Furthermore, similar results of multiple pain conditions in LLA have been reported [6-8].

Factors that may affect how persons answer selfreporting questionnaires were beyond the scope of this study. However, individual characteristics such as depression and social desirability may well have influenced selfreporting of PA behavior. In a study on people with amputation, factors such as young age, traumatic amputation, presence of comorbidities, and presence of multiple pain conditions were reported to increase the risk of developing depression [10]. People with depression tend to underestimate their PA levels when measured with self-report [52], which could have influenced self-reporting PA levels in our sample. In addition, the social desirability associated with surveys tends to overestimate the selfreporting of actual PA levels, which could have biased our results [53]. Future studies should consider the role of such personal factors when measuring PA levels using self-reports in this population.

In terms of other amputation-related parameters, although age at assessment and LBP had a slight negative relationship, the strength of the association $(\beta=0.03)$ was weak. In a previous study of LLA, Ephraim et al. reported the odds of developing LBP decreased in persons $>65 \mathrm{yr}$ [5]. However, conflicting evidence exists for the relationship between age and LBP [4,6-7]. Moreover, similar to other previous studies, years since amputation was not related to LBP $[4,6]$. One possible explanation could be that the majority of our study participants $(85 \%)$ had been using prostheses for more than $10 \mathrm{yr}$, which could have resulted in better adaptation to the prosthesis, leading to efficient gait patterns. Smoking and obesity are well-established risk factors for LBP in the general population [54]. However, smoking history and BMI were not associated with LBP in our sample population.

We adopted a standardized definition of LBP because of the heterogeneity in the methodology and the lack of standardized definition of LBP used in prevalence studies $[1,55-56]$. We recommend using these standardized LBP definitions in future studies exploring LBP in populations with LLA in order to enhance the comparability of study results. Although the response rate for our survey was low $(55 \%)$, the result is comparable with similar previous studies $[4,6,28]$. Further, we adopted simple random sampling to minimize the risk of selection bias and increase the generalizability of our study results [33].

\section{STUDY LIMITATIONS}

First, the results of our study should be interpreted with caution because the study design was cross-sectional and implications pertaining to PA as a risk factor for LBP could not be made. Second, our survey response rate $(55 \%)$ was low and the sampling error of 6.6 percent at 95 percent CI may influence the validity of our results. Moreover, the results of nonrespondents (45\%) could have introduced bias in our results. Third, even though the PASIPD is a standardized questionnaire, conflicting evidence exists to support PA measurement using self-reports [57]. In a recent review investigating the level of agreement between self-reports and objectively measured PA levels in the general population, Prince et al. recommended the possibility of utilizing objective measures in PA measurement [58]. Furthermore, overestimation of PA levels using the PASIPD has also been reported [40]. Fourth, the classification of total PA scores into tertiles could have introduced cut-point bias, which may therefore limit the generalizability of our results.

\section{CONCLUSIONS}

Based on the results of our national cross-sectional survey, we found LBP prevalence to be high (64\%) in persons with traumatic TFA. There is no association between the PA levels of persons with and without LBP. However, the presence of moderate to high PA levels in two-thirds of persons with LBP warrants future investigation into coping strategies employed by this population. Moreover, prospective studies using objective PA measures would elucidate the mechanisms underpinning the relationship (beneficial vs risk factor) between PA and LBP in this population.

\section{ACKNOWLEDGMENTS}

\section{Author Contributions:}

Study concept and design: H. Devan, C. Smith, S. Tumilty. Acquisition, analysis, and interpretation of data: H. Devan, S. Tumilty. Drafting of manuscript: H. Devan, C. Smith, S. Tumilty.

Critical revision of manuscript for important intellectual content: C. Smith, S. Tumilty.

Statistical analysis: H. Devan.

Study supervision: C. Smith, S. Tumilty.

Financial Disclosures: The authors have declared that no competing interests exist. 
Funding/Support: This article was based on work supported by the NZALB.

Additional Contributions: We would like to acknowledge the NZALB for their support and encouragement in survey implementation. We thank Prasath Jayakaran (PhD Candidate, School of Physiotherapy, University of Otago) and Paul Hendrick (Lecturer, School of Physiotherapy, University of Otago) for their critical review of the study proposal.

Institutional Review: The University of Otago Ethics Committee approved this study protocol (Ref 11/061).

Participant Follow-Up: The authors do no plan to inform participants of the publication of this study. However, participants have been informed about the possibility of publishing the study in a scientific journal.

\section{REFERENCES}

1. Hoy D, Bain C, Williams G, March L, Brooks P, Blyth F, Woolf A, Vos T, Buchbinder R. A systematic review of the global prevalence of low back pain. Arthritis Rheum. 2012; 64(6):2028-37. [PMID:22231424] http://dx.doi.org/10.1002/art.34347

2. Turner JA, Cardenas DD, Warms CA, McClellan CB. Chronic pain associated with spinal cord injuries: a community survey. Arch Phys Med Rehabil. 2001;82(4):501-9. [PMID:11295011] http://dx.doi.org/10.1053/apmr.2001.21855

3. Beiske AG, Pedersen ED, Czujko B, Myhr KM. Pain and sensory complaints in multiple sclerosis. Eur J Neurol. 2004;11(7):479-82. [PMID:15257687] http://dx.doi.org/10.1111/j.1468-1331.2004.00815.x

4. Ehde DM, Smith DG, Czerniecki JM, Campbell KM, Malchow DM, Robinson LR. Back pain as a secondary disability in persons with lower limb amputations. Arch Phys Med Rehabil. 2001;82(6):731-34. [PMID:11387575] http://dx.doi.org/10.1053/apmr.2001.21962

5. Ephraim PL, Wegener ST, MacKenzie EJ, Dillingham TR, Pezzin LE. Phantom pain, residual limb pain, and back pain in amputees: results of a national survey. Arch Phys Med Rehabil. 2005;86(10):1910-19. [PMID:16213230] http://dx.doi.org/10.1016/j.apmr.2005.03.031

6. Kulkarni J, Gaine WJ, Buckley JG, Rankine JJ, Adams J. Chronic low back pain in traumatic lower limb amputees. Clin Rehabil. 2005;19(1):81-86. [PMID:15704512] http://dx.doi.org/10.1191/0269215505cr819oa

7. Smith DG, Ehde DM, Legro MW, Reiber GE, del Aguila M, Boone DA. Phantom limb, residual limb, and back pain after lower extremity amputations. Clin Orthop Relat Res. 1999;361(361):29-38. [PMID:10212593] http://dx.doi.org/10.1097/00003086-199904000-00005

8. Taghipour H, Moharamzad Y, Mafi AR, Amini A, Naghizadeh MM, Soroush MR, Namavari A. Quality of life among veterans with war-related unilateral lower extremity amputation: a long-term survey in a prosthesis center in Iran. J Orthop Trauma. 2009;23(7):525-30. [PMID:19633463] http://dx.doi.org/10.1097/BOT.0b013e3181a10241

9. Hagberg K, Brånemark R. Consequences of non-vascular trans-femoral amputation: a survey of quality of life, prosthetic use and problems. Prosthet Orthot Int. 2001;25(3): 186-94. [PMID:11860092] http://dx.doi.org/10.1080/03093640108726601

10. Darnall BD, Ephraim P, Wegener ST, Dillingham T, Pezzin L, Rossbach P, MacKenzie EJ. Depressive symptoms and mental health service utilization among persons with limb loss: results of a national survey. Arch Phys Med Rehabil. 2005;86(4):650-58. [PMID:15827913] http://dx.doi.org/10.1016/j.apmr.2004.10.028

11. Morgenroth DC, Shakir A, Orendurff MS, Czerniecki JM. Low-back pain in transfemoral amputees: is there a correlation with static or dynamic leg-length discrepancy? Am J Phys Med Rehabil. 2009;88(2):108-13. [PMID:19169176] http://dx.doi.org/10.1097/PHM.0b013e318194fbbc

12. Jaegers SM, Arendzen JH, de Jongh HJ. Prosthetic gait of unilateral transfemoral amputees: a kinematic study. Arch Phys Med Rehabil. 1995;76(8):736-43. [PMID:7632129] http://dx.doi.org/10.1016/S0003-9993(95)80528-1

13. Goujon-Pillet H, Sapin E, Fodé P, Lavaste F. Threedimensional motions of trunk and pelvis during transfemoral amputee gait. Arch Phys Med Rehabil. 2008; 89(1):87-94. [PMID:18164336] http://dx.doi.org/10.1016/j.apmr.2007.08.136

14. Waters RL, Mulroy S. The energy expenditure of normal and pathologic gait. Gait Posture. 1999;9(3):207-31. [PMID:10575082] http://dx.doi.org/10.1016/S0966-6362(99)00009-0

15. Waters RL, Perry J, Antonelli D, Hislop H. Energy cost of walking of amputees: the influence of level of amputation. J Bone Joint Surg Am. 1976;58(1):42-46. [PMID:1249111]

16. James U, Oberg K. Prosthetic gait pattern in unilateral above-knee amputees. Scand J Rehabil Med. 1973;5(1): 35-50. [PMID:4804043]

17. Burke MJ, Roman V, Wright V. Bone and joint changes in lower limb amputees. Ann Rheum Dis. 1978;37(3):252-54. [PMID:150823]

18. Desmond D, Gallagher P, Henderson-Slater D, Chatfield R. Pain and psychosocial adjustment to lower limb amputation amongst prosthesis users. Prosthet Orthot Int. 2008; 32(2):244-52. [PMID:18569892]

http://dx.doi.org/10.1080/03093640802067046

19. Friel K, Domholdt E, Smith DG. Physical and functional measures related to low back pain in individuals with lowerlimb amputation: an exploratory pilot study. J Rehabil Res Dev. 2005;42(2):155-66. [PMID:15944880] http://dx.doi.org/10.1682/JRRD.2004.08.0090 
20. Vuori IM. Dose-response of physical activity and low back pain, osteoarthritis, and osteoporosis. Med Sci Sports Exerc. 2001;33(6 Suppl):S551-86, discussion 609-10.

[PMID:11427782] http://dx.doi.org/10.1097/00005768-200106001-00026

21. Kesaniemi YK, Danforth E Jr, Jensen MD, Kopelman PG, Lefèbvre P, Reeder BA. Dose-response issues concerning physical activity and health: an evidence-based symposium. Med Sci Sports Exerc. 2001;33(6 Suppl):S351-58. [PMID:11427759]

22. Haskell WL, Lee IM, Pate RR, Powell KE, Blair SN, Franklin BA, Macera CA, Heath GW, Thompson PD, Bauman A. Physical activity and public health: updated recommendation for adults from the American College of Sports Medicine and the American Heart Association. Med Sci Sports Exerc. 2007;39(8):1423-34. [PMID:17762377] http://dx.doi.org/10.1249/mss.0b013e3180616b27

23. Heneweer H, Vanhees L, Picavet HS. Physical activity and low back pain: a U-shaped relation? Pain. 2009;143(1-2): 21-25. [PMID:19217208]

http://dx.doi.org/10.1016/j.pain.2008.12.033

24. Campello M, Nordin M, Weiser S. Physical exercise and low back pain. Scand J Med Sci Sports. 1996;6(2):63-72. [PMID:8809923] http://dx.doi.org/10.1111/j.1600-0838.1996.tb00073.x

25. Sitthipornvorakul E, Janwantanakul P, Purepong N, Pensri $\mathrm{P}$, van der Beek AJ. The association between physical activity and neck and low back pain: a systematic review. Eur Spine J. 2011;20(5):677-89. [PMID:21113635] http://dx.doi.org/10.1007/s00586-010-1630-4

26. Cooper RA, Quatrano LA, Axelson PW, Harlan W, Stineman M, Franklin B, Krause JS, Bach J, Chambers H, Chao EY, Alexander M, Painter P. Research on physical activity and health among people with disabilities: a consensus statement. J Rehabil Res Dev. 1999;36(2):142-54. [PMID:10661530]

27. Rimmer JH. Health promotion for people with disabilities: the emerging paradigm shift from disability prevention to prevention of secondary conditions. Phys Ther. 1999;79(5): 495-502. [PMID:10331753]

28. Stam HJ, Dommisse AM, Bussmann HJ. Prevalence of low back pain after transfemoral amputation related to physical activity and other prosthesis-related parameters. Disabil Rehabil. 2004;26(13):794-97. [PMID:15371051] http://dx.doi.org/10.1080/09638280410001696683

29. Steinberg FU, Garcia WJ, Roettger RF, Shelton DJ. Rehabilitation of the geriatric amputee. J Am Geriatr Soc. 1974; 22(2):62-66. [PMID:4810416]

30. Pohjolainen T, Alaranta H, Wikström J. Primary survival and prosthetic fitting of lower limb amputees. Prosthet Orthot Int. 1989;13(2):63-69. [PMID:2780262]

31. van den Berg-Emons RJ, Bussmann JB, Stam HJ. Accelerometry-based activity spectrum in persons with chronic physical conditions. Arch Phys Med Rehabil. 2010;91(12):1856-61. [PMID:21112426]

http://dx.doi.org/10.1016/j.apmr.2010.08.018

32. New Zealand Artificial Limb Service [Internet]. NZALS statistics 2009-2010. Wellington (New Zealand): New Zealand Artificial Limb Service; 2010 [cited 2011 Feb 14]. Available from:

http://nzals.govt.nz//assets/Resources/Statistics/Statistics/ Website-statistics-2009-2010.pdf\&pli=1

33. Dillman DA. Mail and internet surveys: the tailored design method. 2nd ed. New York (NY): Wiley; 2000. p. 205-9.

34. Edwards P, Roberts I, Clarke M, DiGuiseppi C, Pratap S, Wentz R, Kwan I, Cooper R. Methods to increase response rates to postal questionnaires. Cochrane Database Syst Rev. 2007;(2):MR000008. [PMID:17443629]

35. Dionne CE, Dunn KM, Croft PR, Nachemson AL, Buchbinder R, Walker BF, Wyatt M, Cassidy JD, Rossignol M, Leboeuf-Yde C, Hartvigsen J, Leino-Arjas P, Latza U, Reis S, Gil Del Real MT, Kovacs FM, Oberg B, Cedraschi C, Bouter LM, Koes BW, Picavet HS, van Tulder MW, Burton K, Foster NE, Macfarlane GJ, Thomas E, Underwood M, Waddell G, Shekelle P, Volinn E, Von Korff M. A consensus approach toward the standardization of back pain definitions for use in prevalence studies. Spine (Phila Pa 1976). 2008;33(1):95-103. [PMID:18165754] http://dx.doi.org/10.1097/BRS.0b013e31815e7f94

36. Serlin RC, Mendoza TR, Nakamura Y, Edwards KR, Cleeland CS. When is cancer pain mild, moderate or severe? Grading pain severity by its interference with function. Pain. 1995;61(2):277-84. [PMID:7659438] http://dx.doi.org/10.1016/0304-3959(94)00178-H

37. Jensen MP, Smith DG, Ehde DM, Robinsin LR. Pain site and the effects of amputation pain: further clarification of the meaning of mild, moderate, and severe pain. Pain. 2001;91(3):317-22. [PMID:11275389] http://dx.doi.org/10.1016/S0304-3959(00)00459-0

38. van der Ploeg HP, Streppel KR, van der Beek AJ, van der Woude LH, Vollenbroek-Hutten M, van Mechelen W. The Physical Activity Scale for Individuals with Physical Disabilities: test-retest reliability and comparison with an accelerometer. J Phys Act Health. 2007;4(1):96-100. [PMID:17489011]

39. Washburn RA, Zhu W, McAuley E, Frogley M, Figoni SF. The physical activity scale for individuals with physical disabilities: development and evaluation. Arch Phys Med Rehabil. 2002;83(2):193-200. [PMID:11833022]

http://dx.doi.org/10.1053/apmr.2002.27467

40. van den Berg-Emons RJ, L'Ortye AA, Buffart LM, Nieuwenhuijsen C, Nooijen CF, Bergen MP, Stam HJ, Bussmann JB. Validation of the Physical Activity Scale for individuals with physical disabilities. Arch Phys Med Rehabil. 2011;92(6):923-28. [PMID:21507382] http://dx.doi.org/10.1016/j.apmr.2010.12.006 
41. Portney LG, Watkins MP. Foundations of clinical research: applications to practice. 3rd ed. Upper Saddle River (NJ): Pearson/Prentice Hall; 2009. p. 393-94.

42. Louw QA, Morris LD, Grimmer-Somers K. The prevalence of low back pain in Africa: a systematic review. BMC Musculoskelet Disord. 2007;8(1):105. [PMID:17976240] http://dx.doi.org/10.1186/1471-2474-8-105

43. Manchikanti L, Singh V, Datta S, Cohen SP, Hirsch JA; American Society of Interventional Pain Physicians. Comprehensive review of epidemiology, scope, and impact of spinal pain. Pain Physician. 2009;12(4):E35-70.

[PMID:19668291]

44. Warburton DE, Nicol CW, Bredin SS. Health benefits of physical activity: the evidence. CMAJ. 2006;174(6):801-9. [PMID:16534088]

http://dx.doi.org/10.1503/cmaj.051351

45. Hasenbring MI, Verbunt JA. Fear-avoidance and endurancerelated responses to pain: new models of behavior and their consequences for clinical practice. Clin J Pain. 2010;26(9): 747-53. [PMID:20664333] http://dx.doi.org/10.1097/AJP.0b013e3181e104f2

46. Wedderkopp N, Leboeuf-Yde C, Bo Andersen L, Froberg $\mathrm{K}$, Steen Hansen H. Back pain in children: no association with objectively measured level of physical activity. Spine. 2003;28(17):2019-24. [PMID:12973151] http://dx.doi.org/10.1097/01.BRS.0000083238.78155.31

47. Diepenmaat AC, van der Wal MF, de Vet HC, Hirasing RA. Neck/shoulder, low back, and arm pain in relation to computer use, physical activity, stress, and depression among Dutch adolescents. Pediatrics. 2006;117(2):412-16.

[PMID:16452360]

http://dx.doi.org/10.1542/peds.2004-2766

48. Lin CW, McAuley JH, Macedo L, Barnett DC, Smeets RJ, Verbunt JA. Relationship between physical activity and disability in low back pain: a systematic review and metaanalysis. Pain. 2011;152(3):607-13. [PMID:21251757] http://dx.doi.org/10.1016/j.pain.2010.11.034

49. Fairbank JC, Couper J, Davies JB, O’Brien JP. The Oswestry low back pain disability questionnaire. Physiotherapy. 1980;66(8):271-73. [PMID:6450426]

50. Meulenbelt HE, Geertzen JH, Jonkman MF, Dijkstra PU. Determinants of skin problems of the stump in lower-limb amputees. Arch Phys Med Rehabil. 2009;90(1):74-81. [PMID:19154832] http://dx.doi.org/10.1016/j.apmr.2008.07.015

51. van Velzen JM, van Bennekom CA, Polomski W, Slootman JR, van der Woude LH, Houdijk H. Physical capacity and walking ability after lower limb amputation: a systematic review. Clin Rehabil. 2006;20(11):999-1016. [PMID:17065543] http://dx.doi.org/10.1177/0269215506070700
52. Huijnen IP, Verbunt JA, Peters ML, Delespaul P, Kindermans HP, Roelofs J, Goossens M, Seelen HA. Do depression and pain intensity interfere with physical activity in daily life in patients with Chronic Low Back Pain? Pain. 2010;150(1):161-66. [PMID:20457489] http://dx.doi.org/10.1016/j.pain.2010.04.021

53. Adams SA, Matthews CE, Ebbeling CB, Moore CG, Cunningham JE, Fulton J, Hebert JR. The effect of social desirability and social approval on self-reports of physical activity. Am J Epidemiol. 2005;161(4):389-98. [PMID:15692083] http://dx.doi.org/10.1093/aje/kwi054

54. Deyo RA, Bass JE. Lifestyle and low-back pain. The influence of smoking and obesity. Spine. 1989;14(5):501-6. [PMID:2524888] http://dx.doi.org/10.1097/00007632-198905000-00005

55. Walker BF. The prevalence of low back pain: a systematic review of the literature from 1966 to 1998. J Spinal Disord. 2000;13(3):205-17. [PMID:10872758] http://dx.doi.org/10.1097/00002517-200006000-00003

56. Leboeuf-Yde C, Lauritsen JM. The prevalence of low back pain in the literature. A structured review of 26 Nordic studies from 1954 to 1993. Spine. 1995;20(19):2112-18. [PMID:8588168] http://dx.doi.org/10.1097/00007632-199510000-00009

57. Stepien JM, Cavenett S, Taylor L, Crotty M. Activity levels among lower-limb amputees: self-report versus step activity monitor. Arch Phys Med Rehabil. 2007;88(7):896-900. [PMID:17601471] http://dx.doi.org/10.1016/j.apmr.2007.03.016

58. Prince SA, Adamo KB, Hamel ME, Hardt J, Gorber SC, Tremblay M. A comparison of direct versus self-report measures for assessing physical activity in adults: a systematic review. Int J Behav Nutr Phys Act. 2008;5(1):56. [PMID:18990237] http://dx.doi.org/10.1186/1479-5868-5-56

Submitted for publication September 1, 2011. Accepted in revised form April 17, 2012.

This article and any supplementary material should be cited as follows:

Devan H, Tumilty S, Smith C. Physical activity and lower-back pain in persons with traumatic transfemoral amputation: A national cross-sectional survey. J Rehabil Res Dev. 2012; 49(10):1457-66. http://dx.doi.org/10.1682/JRRD.2011.09.0155

ResearcherID: Hemakumar Devan, MPhty: G-9585-2012

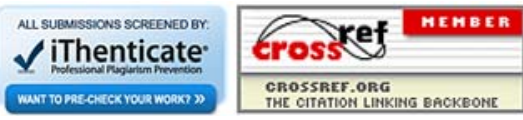

